\title{
Nuestra Madre Milpa Joven: una imagen de la totalidad efímera en un ritual wixárika
}

Notre Jeune Mère champ de maïs : une image de la totalité éphémère dans un rituel wixárika

Our Young Mother Corn Field: an image of ephemeral totality in a Wixárika ritual

\section{Regina Lira Larios}

\section{(2) OpenEdition}

Journals

Edición electrónica

URL: https://journals.openedition.org/jsa/14874

DOI: 10.4000/jsa. 14874

ISSN: 1957-7842

Editor

Société des américanistes

Edición impresa

Fecha de publicación: 15 junio 2017

Paginación: 151-178

ISSN: 0037-9174

\section{Referencia electrónica}

Regina Lira Larios, «Nuestra Madre Milpa Joven: una imagen de la totalidad efímera en un ritual wixárika», Journal de la Société des américanistes [En línea], 103-1 | 2017, Publicado el 15 junio 2017, consultado el 02 septiembre 2022. URL: http://journals.openedition.org/jsa/14874 ; DOl: https:// doi.org/10.4000/jsa.14874 
ARticles 



\title{
Nuestra Madre Milpa Joven: una imagen de la totalidad efímera en un ritual wixárika
}

\author{
Regina LiRa LARIOS *
}

\begin{abstract}
En un ritual agrícola, celebrado en un templo familiar en una comunidad wixárika del occidente de México, se produce un ensamblaje en una secuencia organizada de actos compuesto por elementos heterogéneos, artefactos, partes de animales sacrificados y personas, al que se atribuye la identidad de Nuestra Madre Milpa Joven (Tatei Waxa ‘imari). Analizaremos la forma en que cada una de sus partes es creada y manipulada a lo largo de un ciclo ritual en el seno de las interacciones entre humanos en el patio ceremonial, y entre no humanos en el canto ritual, instaurando relaciones plurales y contradictorias entre personas del mismo sexo, de sexo diferente y entre indígenas y no indígenas. Mostraremos cómo este ensamblaje opera como nodo integrador de los distintos registros de la acción, creando las condiciones para la coexistencia entre los mundos humano y no humano en el acto creativo, con lo que reflexionamos sobre los modos de transmisión indígena a partir de la imagen, el tiempo y el cuerpo. [Palabras clave: ensamblaje, complejidad ritual, imagen de sí, relaciones rituales, temporalidad compleja.]
\end{abstract}

Notre Jeune Mère champ de maïs : une image de la totalité éphémère dans un rituel wixárika. Dans un rituel agricole célébré au sein d'un temple parental dans une communauté Wixárika à l'Ouest du Mexique, un assemblage hétérogène composé d'artefacts, de parties d'animaux sacrifiés et de personnes se produit lors d'une séquence organisée d'actes, auquel on attribue l'identité de Notre Jeune Mère champ de maïs (Tatei Waxa ïimari). Nous verrons comment chacune de ses parties est créée et manipulée au cours d'un cycle rituel au sein des interactions entre humains sur la scène rituelle et entre non humains sur le plan du chant rituel, en instaurant des relations plurielles et contradictoires entre personnes du même sexe, de sexes différents, ainsi qu'entre Amérindiens et non Amérindiens. Nous montrerons comme cet assemblage opère comme noeud intégrateur de registres d'action différents en fournissant les conditions pour que les mondes humain et non humain coexistent dans l'acte créatif. À partir de cela, nous réfléchirons sur les modes de transmission amérindiens dans les rapports entre l'image, le temps

* Becaria Programa de Becas Posdoctorales de la UNAM, Instituto de Investigaciones Históricas [liraregina@yahoo.com.mx]. 
et le corps. [Mots-clés: assemblage, complexité rituelle, image de soi, relations rituelles, temporalité complexe.]

Our Young Mother Corn Field: an image of ephemeral totality in a Wixárika ritual. During an agricultural ritual celebrated in a family shrine in a Wixárika community of West Mexico, an assemblage composed by artefacts, parts of sacrificed animals and persons is produced in the course of an organized sequences of acts and recognized as Our Young Mother Corn Field (Tatei Waxa timari). We will show how each of its parts is created and manipulated throughout a ritual cycle, during interactions among humans in the ritual patio and among non humans in the ritual chant, while establishing plural and contradictory same sex, cross sex and Indian and Non-Indian relations. We will show how this assemblage operates as an integrating node, while establishing the conditions for human and non-human worlds to coexist in creative act. We will thereby reflect on the modes of indigenous transmission in the links between image, time and body. [Key words: assemblage, ritual complexity, self image, ritual relations, complex temporality.]

En el curso de mis estancias de trabajo de campo entre los wixaritari (o huicholes, pl.) del occidente de México, tuve la oportunidad de presenciar una « fiesta » del ciclo agrícola de la temporada seca en varios templos familiares de la comunidad de Santa Catarina Cuexcomatitlán o Tuapurie ${ }^{1}$. Luego de una larga noche de canto, al punto casi de culminar, se produce una escena que siempre capturó mi imaginación: sobre la piedra circular que marca el centro del patio ritual y conecta con el mundo de abajo, y en dirección al oriente, se coloca una silla; se sienta una mujer, y sobre ella se coloca una caja de ofrendas que contiene jícaras, flechas, velas, discos votivos, partes de un venado cazado y de una res sacrificada; sobre ésta se extienden velas encendidas a manera de un abanico y al zénit brilla el sol de mediodía. Todos los ejecutantes del ritual se

1. Las sociedades wixaritari o huicholas viven en los estados de Jalisco, Nayarit, Durango y Zacatecas, entre la costa del Pacífico, los márgenes del río Santiago y el sur de la Sierra Madre Occidental, territorio que habitan desde tiempos prehispánicos. Las comunidades indígenas agrarias conforman aproximadamente 400 mil hectáreas y se organizan en cinco gobernancias, además de los ejidos adyacentes, las poblaciones desplazadas y los territorios en disputa. El huichol o wixárika pertenece a la familia lingüística yuto-azteca, dentro del cual forma un sub-grupo con el cora. Las reglas de ortografía del wixárika son aún objeto de debate entre especialistas y hablantes que disputan las variantes regionales. Me he apegado a la ortografía aplicada en la comunidad de Tuapurie Santa Catarina Cuexcomatitlán (municipio de Mezquitic, estado de Jalisco), donde he realizado la mayor parte de mi investigación durante estancias de trabajo de campo realizadas entre los años 2007 y 2010 gracias al apoyo del Programa Becas en el Extranjero del CONACYT y al Laboratorio de Antropología Social del Collège de France. El trabajo de transcripción y traducción del canto ritual se llevó a cabo gracias al apoyo de la Firebird Foundation Project for Oral Litterature. La redacción de este artículo se elaboró gracias al Programa de Becas Posdoctorales de la Universidad Nacional Autónoma de México. 
Nuestra Madre Milpa Joven: una imagen de la totalidad efímera en un ritual wixárika

concentran en torno de este conjunto heteróclito, el cantador-chamán de frente, los hombres ungiendo sangre y las mujeres rociando agua sobre las ofrendas; todos guardan contacto los unos con los otros con lágrimas en los ojos. Sobre este ensamblaje perfectamente ordenado he preguntado en diversas ocasiones: «¿qué es? », y cada vez se me respondió: « Nuestra Madre Joven Milpa. »

¿Cómo es que las partes heterogéneas que la componen pueden ser concebidas como un todo? ¿Cómo se atribuye de una identidad a algo tan efímero? ¿Bajo qué principios se produce este reconocimiento? ¿Por qué produce tanta tristeza? ¿En qué radica el efecto que produce? En fin, ¿cómo nombrar y entender lo que a mis ojos resultaba une ensamblaje tan extraño y perfecto? Intentaré responder a estas preguntas al demostrar que la Madre Milpa Joven es la imagen heterogénea, plural y efímera que la sociedad wixárika (huichol, en sg.) crea de sí misma, basada en dos propuestas. La primera en una noción de imagen formulada desde una perspectiva relacional y performativa a partir de la etnología melanesia, que ha puesto de relieve las formas específicas en las que las personas se presentan « a sí mismas ante sí mismas », sea en forma artefactual, corporal, en performances u otras (Strathern 2013, p. 157; Gell 1998; Schieffelin 1985)². La segunda, en la exploración de los procesos de construcción de una representación social o identitaria que no se remiten a la elaboración de un discurso, sino a la puesta en forma y en acto de relaciones particulares (Severi 2003, p. 8; Houseman 2006, p. 413), como ha demostrado la teoría del ritual enfocada desde la pragmática (Bloch 1974; Schieffelin 1985; Humphrey y Laidlaw 1997; Houseman 2000, 2012; Severi 1996, 2007)33.

Como vía para examinar el ensamblaje Madre Milpa Joven desde la complejidad ritual, veremos cómo cada una de las partes que la componen es creada y manipulada a lo largo de un ciclo ritual. Con base en la etnografía presentada en un primer apartado, veremos el papel de los artefactos que la componen en la producción de personas en el ritual, primero en el seno de las interacciones entre participantes en el patio del templo, después en el seno de las interacciones entre los antepasados en el canto ritual. Los artefactos serán diferenciados entre sí a partir de las relaciones que estos ponen en juego entre personas del mismo sexo, entre personas de sexo diferente y entre huicholes y no huicholes (Lira 2014). Así entenderemos a la Madre Milpa Joven como

2. Me baso en la definición de imagen de sí que M. Strathern ha desarrollado en el contexto etnográfico melanesio, quien dice «People objectify or present themselves to themsleves in innumerable ways, but must always do so through assuming a specific form » (2013), p. 157). En la etnología melanesia la performance como forma de auto-representación, como medio de transmisión o como objeto de arte que actúa en el mundo desde la perspectiva citada ha sido elaborada por M. Strathern, pero también por E. Schieffelin y A. Gell.

3. Es de M. Houseman de quien he tomado la traducción del inglés enactment al francés (" mise en forme et en acte ») que he traducido al español como " puesta en forma y en acto » (2012). 
emergente de un campo relacional que implica a todos los participantes humanos y no humanos, a sus actos e interacciones, y opera como nodo integrador de los distintos registros de la acción que le dan su aparente soporte, y son tanto paralelos como independientes en la medida en que cada uno hace el ritual (Houseman y Severi 1994; Bateson 1958).

Pondremos especial atención en los siguientes aspectos. En primer lugar, en su forma arquitectónica (Bakhtin 1990 [1920-1923], 1990 [1924]), es decir la manera en que el ensamblaje es construido y las relaciones que éste ordena, abordando cada uno de sus componentes como índice visible de relaciones invisibles emergentes de la interacción entre personas en el tiempo y en el espacio que cumplen una función composicional y organizativa de la práctica ritual. En segundo lugar, en el modo en que produce una imagen efímera de la totalidad, que hemos llegado a entender como un modo de actuar en el mundo y de conocerlo, en cuyo efecto altamente emotivo reside tanto su novedad como su poder y sus posibles significados (Kindl 2007; Freedberg 1989, p. 432). Como creador y contenedor de tiempos, este objeto complejo va más allá del tiempo anacrónico que la obra de arte suele generar (Moxey 2013), y nos remite en cambio a una temporalidad múltiple al involucrar una técnica de coordinación y de sincronización de espacios-tiempo en la acción colectiva, abriendo preguntas sobre los modos de transmisión dados a partir de la imagen, el tiempo y el cuerpo.

\section{La cacería y la agricultura desde el enfoque relacional al ritual}

He dedicado un análisis detallado a este ritual centrado en los actores, sus prácticas y en la enunciación de un canto ritual (Lira 2014), retomando una de las grandes preguntas antropológicas en la etnología del Gran Nayar: las relaciones entre la cacería y la agricultura, que en el caso wixárika han sido abordadas especialmente en el estudio de los rituales comunitarios con base en el análisis sobre las estructuras simbólicas y las prácticas sacrificiales (Furst y Schaefer 1996; Gutiérrez del Ángel 2002; Kindl 2003; Neurath 2002). En mi experiencia, la práctica etnográfica en los templos comunitarios tukipa es limitada por las autoridades tradicionales, pues se trata, en palabras suyas, de « su secreto ». Si bien se me permitió presenciar los rituales comunitarios, se me negó la participación a la peregrinación al desierto de San Luis Potosí, y fue en el ámbito familiar de diversas rancherías que pude realizar mis investigaciones. En mi observación de los rituales en ambos ámbitos ceremoniales - el familiar del templo xiriki y el comunitario del conjunto tukipa - constaté que en el familiar se ejecutan las secuencias que se realizan en la mayoría de los rituales que implican la cacería de venado y el sacrificio de una res (vaca o toro); es decir, aquellas secuencias ligadas al ciclo agrícola que en el ámbito comunitario 
Nuestra Madre Milpa Joven: una imagen de la totalidad efímera en un ritual wixárika

implican un mayor número de participantes, días, sacrificios y una mayor elaboración en su ejecución, lo que dificulta la posibilidad de ser etnografiadas de manera individual. La etnografía a nivel familiar resultó adecuada ya que el xiriki es la base de la estructura social como red de relaciones de parentesco y de intercambio ${ }^{4}$. El xiriki es un nodo dentro de una red de rancherías que en la dimensión político-territorial se liga con una agencia y con su cabecera, y en la religiosa se liga con una red de xirikite (-te marca del plural) parentales, con los templos ceremoniales (tukipa) y con los sitios sagrados (kakatyarite). Es en la ranchería que la vida cotidiana transcurre y los miembros de una familia extendida atienden sus responsabilidades rituales, incluso cuando han emigrado o rechazan la participación en los templos comunitarios (Liffman 2011, p. 97)

La westa (huicholización del término « fiesta ») que aquí analizaremos forma parte del ciclo ritual de la temporada de secas (tukari) que se celebra - en principio - cada año, y ocurre después de la cacería de venado y la quema del coamil y antes de la siembra de maíz ${ }^{6}$ (ver Figura 1, página siguiente). En ella participan miembros de una familia extendida convocados por el jefe de una ranchería donde se mantiene el templo familiar-xiriki en el que se veneran los ancestros comunes, tanto los ancestros deificados que fundan el culto familiar xiriki - Hermano Mayor Venado Tamatsi Kauyumarie y la Madre Maíz Tatei Niwetsika ${ }^{7}$, como los ancestros genealógicamente demostrables que pueden remontar a hasta cinco generaciones y están presentes en su forma « enfriada » al interior de las jícaras-ancestros conservadas en el templo. La participación dependerá del grado de proximidad parental a los ancestros venerados, del nivel

4. Sobre la etnografía a nivel del xiriki parental, K. Preuss documentó fragmentos en distintas rancherías de comunidades en Nayarit y Jalisco (1998 [1908]), R. Zingg fue el primero en documentar todo un ciclo ritual en una ranchería y en el centro ceremonial de Ratontita en los confines entre Tuxpan de Bolaños y San Sebastián Teponahuastlán en 1938, pero es J. Neurath quien logró articular el ciclo ritual anual celebrado a nivel familiar xiriki, comunitario tukipa y en la cabecera, en su tesis de doctorado publicada en 2002.

5. P. Liffman atribuye una importancia particular a los rituales del xiriki ya que en San Andrés Cohamiata, la comunidad donde ha realizado sus investigaciones, la legitimidad de ciertas instancias de poder está en declive y ha perdido la capacidad de englobar simbólicamente a la comunidad entera, un proceso que desde los años 1960 era observado en San Sebastián Teponahuastlán por P. Weigand (1992, p. 48). Según P. Liffman, como consecuencia de esta crisis de legitimidad, la vida ritual en los xiriki ha cobrado mayor importancia, y « la jerarquía se ha invertido » $(2011$, p. 89). No es el caso en Santa Catarina, donde de hecho la jerarquía de los templos comunitarios (tukipa) se mantiene por encima de la cabecera, si bien las relaciones de poder alternan según los periodos del año.

6. Este ciclo se complementa con otro ciclo que se ejecuta durante la temporada de aguas o tìkari.

7. El culto a estos ancestros es común a todos los templos familiares-xirikite (-te, marca del plural), y además cada uno se ocupa de la renovación de un número de relaciones rituales que puede variar entre templos al haber sido adquiridos por herencia o bien porque el responsable de hacer la fiesta las ha adquirido como nuevos pactos o deudas a lo largo de su vida. 


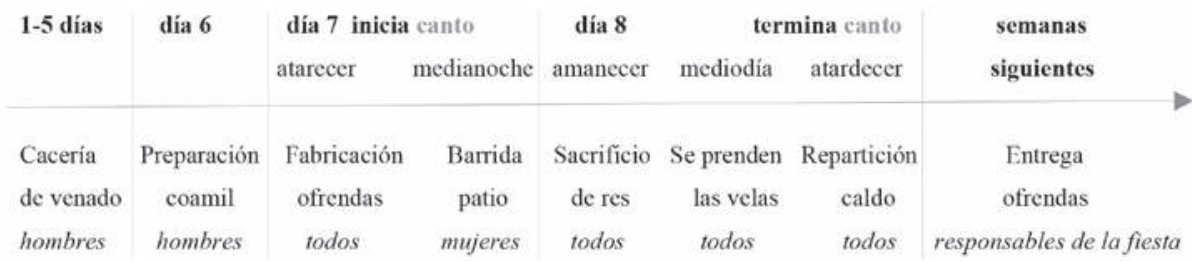

Fig. 1 - Cronología del ciclo ritual durante la temporada de secas en un templo familiar.

de aprendizaje ritual adquirido en su participación en el sistema de cargos, así como también de la edad y el sexo.

El cantador-chamán (mara'akame) es escogido por el jefe de la ranchería con acuerdo del grupo familiar por un ciclo de cinco años. Dirige la sesión ritual con un canto que dura aproximadamente desde antes de la medianoche hasta el atardecer del día siguiente, auxiliado a sus costados por dos dirigentes de la cacería ('awatamete) que son sus « segunderos» (kwinepuwamete) y por los músicos que intervienen por lapsos, un guitarrista kanareru y un violinista xawereru. Como guía del grupo tiene la importante responsabilidad de cumplir con las expectativas de un auditorio compuesto por personas con distintos grados de aprendizaje, que no dudarán en cuestionar su autoridad si no cumple con los objetivos del ritual: cazar venado, hacer crecer maíz, traer lluvias, propiciar la salud de los familiares, los animales y la milpa. Su naturaleza paradójica involucra una identidad que es simultáneamente humana y no humana, que en el canto resulta en una identidad múltiple casi abrumadora (Severi 2002; Hanks 2009). Los dos niños haakeri, también designados por cinco años, son los aprendices de la tradición y « como venados » (una hembra y un macho) portan en su oreja una vara de plumas que simboliza su cuerno; y a la vez, su proximidad con la res destinada al sacrificio en las secuencias preparatorias del sacrificio los vincula simbólicamente con ella. A diferencia de los demás niños que se encuentran al margen de la escena ritual, y se ocupan de ayudar con las actividades manuales (acarrear agua y leña, preparar y distribuir alimentos), ellos gozan de una perspectiva interna del trabajo ritual, situados al lado del cantador y de los segunderos, quienes les indican cuándo deben manipular los objetos más « delicados »: las ofrendas, las herramientas agrícolas y, para la cacería, los utensilios para el sacrificio. La pareja de casados que « entregan la ofrenda » (timawamete, de mawari ofrenda, o mawarixa, sacrificio) es nombrada por un ciclo entero (aguas y secas). Son los responsables de comprar la res y de todo lo necesario para la realización del ritual, así como de depositar las ofrendas en los « ancestros-topónimos » de mayor jerarquía en las semanas subsecuentes.

Los hombres del grupo serán nombrados de manera diferente según las etapas del ciclo: Animales Cazadores ('Awatamete) durante los cinco días de cacería, 
Nuestra Madre Milpa Joven: una imagen de la totalidad efímera en un ritual wixárika

Coamileros (Watakamete) en los días dedicados a la preparación del campo de cultivo con la quema del coamil, o Hermanos Mayores Venado (Tamatsima) durante la fiesta ${ }^{8}$. Su modo de hacer implica destreza y precisión: para cazar con rifle, manipular el fuego en la quema del coamil o para sacrificar y destazar la res. Para tener éxito en cada una de estas etapas los hombres deben actuar de manera colectiva, en estricta coordinación y con alto control de sí, a pesar del cansancio y las abstinencias impuestas. Las mujeres del grupo son las madres genitoras, nombradas a su vez de manera diferente en cada etapa del ritual: como Madres de la lluvia y de la noche (Tateteima) durante la cacería (espacio del cual son excluidas), y como Madres Maíz (Niwetsika) durante la preparación del coamil y la fiesta. Su modo de hacer contrasta significativamente con el de los hombres: ejecutan sus actos de manera extremadamente ordenada y sigilosa. Llevan consigo las jícaras-ancestros heredadas de los antepasados venerados en el templo familiar, que manipulan a lo largo del ritual entre el interior del templo, el centro del patio y frente al fuego (simbólicamente asociados con el mundo de abajo, el de en medio y el de arriba). Según la exégesis masculina, las mujeres « están más cerca de los dioses » y no necesitan « ni hacer tanto ni ir tan lejos » en su proceso de aprendizaje, ya que su poder genésico está dado de antemano.

La configuración relacional de este rito se organiza en torno de tres posiciones ocupadas por dos hombres y una mujer, con lo cual he introducido el papel femenino al análisis de las relaciones rituales. Estas serán ocupadas por todos los miembros de la familia en los años venideros, ya sea por suerte o por designación del cantador-chamán, y de ellas depende la transmisión intra (horizontal) e inter (vertical) generacional del trabajo ritual.

Las identidades rituales de estas tres personas sólo son comprensibles al interior de una red modificada de relaciones de parentesco de las que emergen por condensación de términos contradictorios (Houseman y Severi 1994). Estos términos son proporcionados por los participantes que se nombran a sí mismos en el curso de las secuencias rituales (por ejemplo al ser cazadores y venados), y por el canto ritual que proporciona nuevos términos que complejiza sus identidades y nos permite reconstruir los vínculos de parentesco entre ellas: una mujer madre-jícara (tei xukuri), un hombre hermano mayor venado (Tamatsi Kauyumarie) que a la vez es hermano menor tigre (Wawatsari nemuuta) ${ }^{9}$, y

8. Los términos en español no son traducciones literales de los términos en huichol, sino que son los que me proporcionaron mis interlocutores. Por ejemplo, 'Awatamete es literalmente personas-cuerno, pero designa a los cinco cazadores míticos que son guardianes del fuego.

9. No nos detendremos en la demostración de las reglas matrimoniales implícita en el ritual. Precisamos sin embargo algunos elementos claves para su comprensión. -Matsi es un término de parentesco correspondiente a un hermano mayor y/o primo mayor bilateral, y -muuta corresponde a hermano menor y/o primo menor bilateral. Ambos designan una relación de hombre a hombre. El matrimonio preferencial se realiza entre miembros de una 
un hombre hijo-flor $\left(\right.$ nuiwari $^{10}$ ) que a la vez es hermano menor tigre (-muuta), el joven sacrificador que será simbólicamente sacrificado al amanecer y es identificado con el nacimiento del sol.

La familia nuclear primigenia es restituida mediante la instauración de relaciones rituales plurales que, tal como ha señalado J. Neurath (2008a, 2008b), se remiten a distintas esferas de intercambio - de cacería y de agricultura -, pero que analizadas en el seno de las relaciones sociales son la expresión de una doble diferencia - de género y de alteridad - y se expresan en el lenguaje del parentesco - colateralidad (afinidad potencial) y consanguinidad. Las relaciones rituales emergentes entre estas tres posiciones no son solamente esenciales para la definición de sus identidades, sino que coinciden con su gestación, extendiendo los lazos entre participantes más allá de las fronteras biológicas al aludir al origen ancestral y a la procreación. Estas mismas actualizan y hacen visible el vínculo entre Nuestra Madre Maíz y Nuestro Hermano Mayor Venado: el vínculo primordial que funda el culto a los ancestros practicado en el templo-xiriki familiar que se renueva en cada ritual « como si fuera la primera vez ».

Del campo relacional en el que todos los participantes se encuentran implicados emerge la identidad mujer-maíz, posición ocupada por la mujer con el cargo de timawame (« que entrega la ofrenda »), llamada madre-jícara (tei xukuri) en el canto, sobre la cual se forma el ensamblaje Nuestra Madre Milpa Joven (Tatei Waxa ‘imari), objeto de este análisis. Veamos ahora cómo se crean los demás artefactos, las jícaras, flechas, discos votivos y objetos sacrificiales, que compondrán este ensamblaje durante la secuencia « se prenden las velas » (haurimantiyani).

\section{La puesta en forma y en acto de la Madre Milpa Joven}

Un día, durante una ceremonia, se me dijo: « ¿Cómo ves la costumbre de los huicholes? Tenemos que usar mucho la cabeza y ver cómo vamos a acordarnos. Hay que memorizar y memorizar. Entonces ya hacemos la fiesta, y ya está. »

misma familia, no en línea directa sino entre ego y primos/as, tío/a, sobrino/a. Por ello -matsi puede designar al hermano mayor, al primo mayor o al esposo potencial de hermana o prima de -muиta. En consecuencia, -muиta puede designar a hermano menor o primo menor de la esposa de -matsi (o la madre de -niwe). Al llevar la regla a su extremo, se designa una relación de afinidad potencial con lo cual se completa la condensación de términos contradictorios de parentesco: el joven sacrificador se identifica con el tío materno y el cazador se identifica con el hermano/primo menor de esposa, implicando la transgresión de la regla matrimonial que prohíbe el incesto en línea directa. Los términos de parentesco, que por lo general son acompañados de un posesivo como prefijo, pueden aparecer sin ellos en el canto, como sucede en el caso de matsi. En el texto no añadí el posesivo en la traducción: -ta es « nuestro » $\mathrm{y}-n e$ es « mi ». Los términos de parentesco fueron tomados de A. Manzares (2003, p. 81) y cotejados en B. Grimes y J. Grimes (1962).

10. Este término es traducido por el lingüista G. Pacheco como « nacimiento », y en los cantos trabajados por D. Lemaistre (2003, p. 35) su traductor propuso hacerlo como « descendiente ». 
Nuestra Madre Milpa Joven: una imagen de la totalidad efímera en un ritual wixárika

Sobre este « memorizar y memorizar » la observación y la participación que me fue permitida me llevó a entender que los artefactos son el núcleo en torno al cual se organiza la acción ritual: la fiesta comienza con su fabricación al atardecer, prosigue con su manipulación en el altar ubicado al interior del templo familiar (Este), el patio (Centro) y junto al fuego (Oeste) durante la madrugada, y culmina con su ensamblaje al mediodía, para finalmente ser desagregados y entregados a cada sitio sagrado-ancestro en las semanas subsecuentes (ver Figura 2). En el canto, los artefactos también cumplen una función arquitectónica tanto a nivel micro como macro del texto ritual. A nivel de pasajes que se distinguen por su contenido narrativo estructurado por desplazamientos, manipulación y depósito de artefactos, que producen un subsecuente « retoño » (de la raíz verbal -weni « retoñar, desplegar, ofrendar »). Y a nivel de bloques, asociando artefactos con entidades y regiones del mundo que esbozan los principios generales de un arte de la memoria wixárika (Yates 2004 [1975]). Tanto en la escena ritual como en el canto, las secuencias de acciones en las que participan los actores humanos y no humanos ofrecen perspectivas dispares, discontinuas y fragmentarias, que parecen crear una experiencia del tiempo y del espacio característica del rito. A la inversa, la manipulación de los objetos permite reconstruir una trayectoria continua del trabajo ritual, lo que a su vez produce una experiencia espacio-temporal también propia al ritual y que coexiste con la anterior. Mientras por un lado los humanos se inscriben en la escena ritual como objetos, por el otro los objetos se comportan en el canto como humanos. En fin, el modo en que ambas configuraciones se imbrican y articulan le confiere a los artefactos

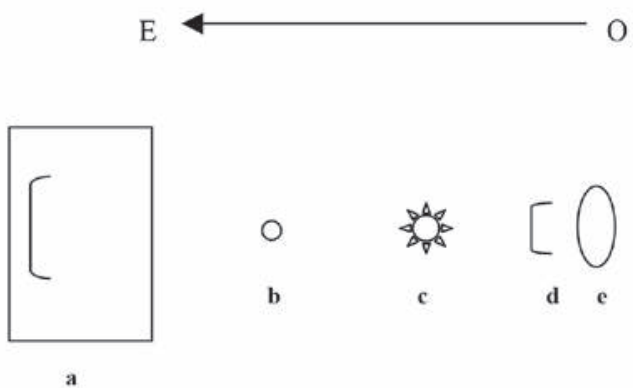

\footnotetext{
a: Templo xiriki, la puerta en dirección al Oeste. Al interior, en el extremo oriental se ubica el altar.

b: Centro del patio ritual, marcado por el tepari que conecta con el mundo de abajo.

c: Fogata.

d: Herramientas chamánicas esparcidas frente al cantador, sobre su tapete ('itari).

e: Posición del cantador-chamán (mara'akame), en su equipal ('uweni), mirando al Este.
}

Fig. 2 - Croquis del espacio ritual en una ranchería de la comunidad de Tuapurie. 
y a las imágenes que de ellos se desprenden un papel central en la producción de simbolismo y en la circulación y transmisión de conocimientos en el ritual.

Al ser el núcleo en torno del cual se estructura el rito, nuestra atención sobre la fabricación y manipulación de artefactos nos llevó a apreciar el cuidado con el que las mujeres crean los diseños al interior de las jícaras, los colores empleados en el dibujo de las flechas fabricadas por los hombres, el orden levógiro con el que el cantador dibuja los motivos en los discos votivos, o el modo en que todos decoran y nombran las velas. En este cuidado al hacer, se demuestra si una persona « tiene corazón » o 'iyari, concepto que remite tanto a la entidad anímica común a todos los seres existentes como también a la habilidad de una persona para recordar. Gracias a un proceso de sensibilización de la mirada estimulada por los interlocutores, entendemos que cierto tipo de imágenes crean las condiciones de posibilidad para la comunicación con los ancestros (de manera inversa, las imágenes inducidas por el consumo ritual de peyote o en los sueños se conciben como el recurso por excelencia de los ancestros para comunicar con los humanos). Esta « comunicación » con los ancestros se traduce en la expresión « un solo corazón » del discurso ritual, en la cual corazón o 'iyari también designa una memoria compartida que reside en el corazón y se transmite (Schaeffer 2002, p. 53), la cual remite al pensamiento y al entendimiento que se adquiere con un " corazón límpido » (Negrín 1985, p. 35) ${ }^{11}$. Esta memoria compartida por humanos y ancestros se crea y se transmite en la manufactura y manipulación de los artefactos, que crean a su vez un espacio compartido articulado en torno de la mujer-jícara, como veremos a continuación.

Tanto por su técnica de fabricación, materiales, significados y como herramientas de poder, los artefactos rituales huicholes han sido uno de los objetos de reflexión recurrentes en una producción de conocimiento etnográfico que rebasa los cien años (Lumholtz 1904a y 1904b; Preuss 1998 [1907], 1998 [1908]; Zingg 1982 [1938]; Furst 1972; Negrín 1985; Kindl 2007; Neurath 2013; Lira 2014). Aquí nos dedicaremos a mostrar sus contextos de uso en el ritual.

11. El 'iyari se entiende en relación al kípuri traducido como «alma vital » 0 « rocío » que anima a los seres existentes, sean personas, plantas, minerales, animales o ancestros deificados. Este concepto ha sido abordado por la mayoría de los autores que han estudiado el chamanismo huichol, y coinciden en su traducción como corazón y memoria (ver, entre otros, Negrín 1985; Lemaistre 2003; Kindl 2007). O. Kindl además lo designa como una «facultad conceptual y emocional » (2007, p. 367). S. Schaefer describe 'iyari como «a kind of inherited memory that resides in the heart and is passed down from the ancestors. The 'iyari is an entity that exists independently of an individual human being, and is associated with thought, experience, and understanding » (2002, p. 53) 
Nuestra Madre Milpa Joven: una imagen de la totalidad efímera en un ritual wixárika

\section{Producción de personas como artefactos en el patio ritual}

En la primera secuencia, « se fabrican las ofrendas » (metehauwewieni) se inaugura el ritual. Convocados al atardecer, todos los familiares se reúnen en el centro del patio ritual y terminan de decorar las ofrendas: los hombres hacen las flechas, las mujeres las jícaras, el cantador los discos votivos y las velas son distribuidas a todos los familiares y adornadas con una flor en papel de china. Según lo documentó K. Preuss, los objetos de uso ritual que llamaba « instrumentos para ver » pertenecían originalmente a los antepasados, y los hombres no hacen más que tomarlos « prestados » al « renovarlos » (1998 [1907], p. 183; 1998 [1908]). En el hacer como los antepasados se produce un desdoblamiento de la identidad del participante que es a la vez pariente y actor ritual, y los objetos se convierten en índice de su nueva posición: al hacer flechas son hermanos mayores venados, al hacer las jícaras son madres maíz, al hacer los discos votivos el cantador es abuelo fuego (entre otros). En el acto de su inscripción al ritual se opera la transferencia de agencia - secundaria en términos de A. Gell (1998) - sobre el objeto, y en el marco del ritual esto conduce a que humanos y antepasados no sólo se llamen de la misma manera sino a que hagan lo mismo; es decir, se trata de una paulatina sincronización y coordinación de actividades que producen un espacio compartido, o bien lo que entre los mixe de Oaxaca P. Pitrou ha llamado el establecimiento de un régimen de co-actividad (2012, p. 80) ${ }^{12}$.

Durante la cacería que se llevó en una etapa previa a la westa se cazó un venado gracias a la suerte y destreza de un cazador. De este acto se produjo el rostro de venado, llamado nierika ${ }^{13}$, que el cantador sostiene en su mano mientras canta y orienta hacia las direcciones cardinales con su vara de plumas (muwieri), y manipula con el resto de las ofrendas. En el amanecer de la fiesta el sacrificador empuña un cuchillo en la yugular de la res por instrucción del cantador. De este acto se produjeron unos cuernos de res, que junto con el corazón y el hígado se colocan con el resto de las ofrendas. El rostro de venado y los cuernos de res son el índice de una relación condensada que engendra la identidad ritual de Cazador-venado que adquiere diversos nombres en el canto,

12. P. Pitrou (2012, p. 80) encontró entre los mixe de Oaxaca entidades a los que se les atribuyen actividades que « inventan o moldean las formas del mundo », como lo haría un ceramista o un tejedor. En esta organización dada por actividades específicas, que P. Pitrou analiza en la creación de depósitos mixe, es que propone lo que llama « régimen de co-actividad » y dice: "Lors de la réalisation d'un dépôt, l'extension de la sociabilité à un partenaire ontologiquement différent ne s'effectuerait donc pas seulement selon la logique de l'échange réciproque, elle correspondrait également à un désir d'initier des mouvements afin qu'un autre, réputé les observer, puisse les réaliser à son tour » (p. 98). Esta idea cobra sentido en la etnografía huichola y podría desarrollarse más.

13. Regresaremos sobre este concepto nativo particularmente complejo que designa tanto un tipo de artefactos de uso ritual, como un modo de conocimiento propio al aprendizaje chamánico. 
entre los cuales figuran el hermano mayor cazador-venado Tamatsi Paritsika, y el de Sacrificador-res, que en el canto se designa flor-xuturi y será identificado con el nacimiento del sol, Nuestro Ancestro Takałye ${ }^{14}$. Todos estos artefactos son colocados en una caja en el altar, al interior del templo.

Este modo de fabricar artefactos puede ser entendido como un sistema ritual de producción de personas según lo propuso M. Strathern entre los hagen, donde hay relaciones que producen objetos (cross-sex) y objetos que producen relaciones (same-sex) (Strathern 1990; Gell 1999). Pero hay que notar que aquí no todos los objetos comparten el mismo estatus de agencia o persona, y que hay tanto relaciones directas como indirectas al objeto. Por ejemplo el cantador, por su naturaleza paradójica que pre-existe al ritual, establece relaciones directas con los ancestros - de uno a uno - a través de los discos votivos en los cuales dibuja el rostro de cada uno (para él cada nierika es el « rostro » de un ancestro con sus ojos, boca, nariz, orejas, « como una persona »), mientras que para el resto de los participantes su relación con los ancestros es mediada por el cantador, los objetos, sus acciones e interacciones. Aquí tenemos objetos que producen relaciones (simétricas o de rivalidad) entre personas del mismo sexo: las flechas inscriben a los hombres como cazadores por un lado, y las jícaras a las mujeres genitoras por el otro. Y de la relación (asimétrica o de diferencia) entre ambos se producen objetos como personas, con lo que tenemos a la categoría de objetos vinculados con el sacrificio (velas, rostro de venado, cuernos de res) (ver Figura 3).

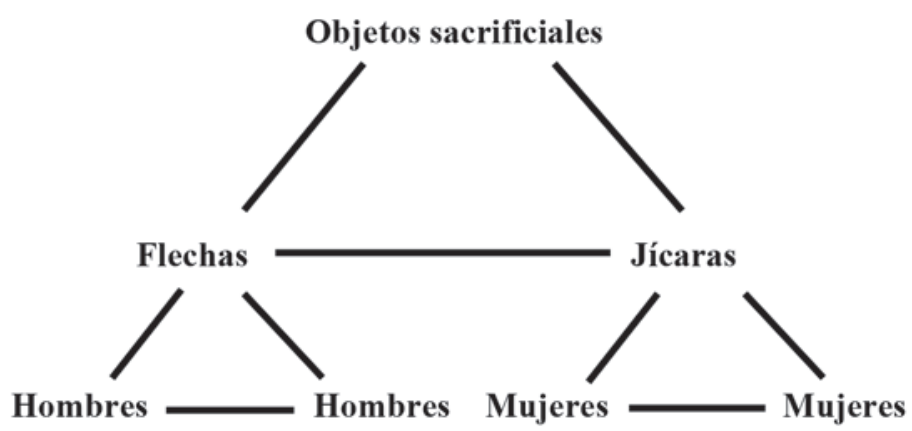

Fig. 3 - Relaciones acumulativas que dan forma a la Madre Milpa Joven.

14. El término "-kaiye » quiere decir literalmente « ancestro », y lo encontramos en el canto con los posesivos - ne (mi) o -ta (nuestro). Es el término ritual para designar al sol según me indicaron los especialistas rituales. Así lo confirma R. López de la Torre (2006) en su libro sobre mitología wixárika, donde señala que un niño « pobre e inválido » se entregó el fuego en el poniente y tomó el nombre de Tamatsi Xautarika, pero que al emerger en el oriente se convirtió en el « vocero del sol » y tomó el nombre de Tamatsi Parikita Muyeika, pero cuando finalmente ascendió en el cielo fue nombrado Takaiye, que traduce como « nacimiento del gran poder» (p. 24-25) y como « Sol mayor » (ibid., p. 34). 
Si hasta el momento la configuración relacional ha dado cuenta de la identidad ritual de la mujer-maíz ( « la que entrega la ofrenda ») y mujer-jícara en el canto como emergente de un campo relacional que implica a todos los participantes y sus interacciones, los artefactos fabricados en el marco ritual son el índice visible de las relaciones invisibles entre personas del mismo sexo, de sexo diferente, y con sus antepasados mediante procesos de identificación directos e indirectos. Sin embargo, el orden que adquiere este entramado relacional dado por la diferencia sexual no es suficiente para dar cuenta de la complejidad que los objetos sacrificiales adquieren en el canto, y que concierne la relación con los no indígenas, es decir los mestizos.

\section{Producción de artefactos como personas en el canto ${ }^{15}$}

En su inserción en el mundo-otro en el curso de la enunciación del canto ritual, los artefactos orientan la imaginación de los ejecutantes del rito. Por él transcurren una diversidad de objetos/imágenes: nierika-rostro, vara de plumas, mazorcas de maíz, equipal, cruces, tapete, flechas, jícaras, vela, flor, cirio, título y otros. Entre estos sólo algunos son mencionados de manera recurrente y dotados de atributos humanos: nacen, crecen, hablan, ven, se desplazan, se colocan. A veces son designados como plantas que crecen, frutos que maduran, flores que retoñan, o bien como venados enlazados que quedan suspendidos en el aire como plumas. Acompañados de posesivos en $1^{\text {a }}$ (mi o -ne), $2^{\text {a }}$ (tu o -a) y $3^{\text {a }}$ ( su -0) persona, son atribuidos a distintas entidades en distintos planos espacio-temporales (derecha/sur, izquierda/norte, arriba/este o abajo/poniente), que terminan por confluir en el posesivo « nosotros » y en un « centro » que es el aquí-ahora de la enunciación. Entre los mencionados recurrentemente, un tratamiento lingüístico especial nos ha revelado los principios de funcionamiento de un pensamiento taxonómico poniendo en evidencia relaciones paradigmáticas entre artefactos que son reforzadas por el uso de deícticos que los agrupa en tres categorías: la categoría-jícara, manipulada por las entidades femeninas; la categoría-vara de plumas, manipulada por las entidades masculinas; y la categoría-flor-xuturi, que se vincula con los anteriores y con las entidades mestizas y agrupa artefactos ligados con el sacrificio. La manipulación e intercambio de algunos de estos artefactos tiene como consecuencia un acto de

15. Los análisis derivados del canto ritual (wawi) se basan en la transcripción y traducción de la primera parte de un canto (de un total de cinco partes), realizada con la autorización del cantador-chamán en su templo familiar, ya que el registro de cantos en los centros ceremoniales tukipa está prohibido por las autoridades tradicionales. La transcripción y traducción fueron realizadas gracias a la colaboración con los lingüistas Gabriel Pacheco y Angélica Ortiz, el traductor Totupica Candelario y asimismo en consultas específicas con especialistas rituales. 
« transformación » o « retoño » que, según me explicaron, evoca la emergencia o el nacimiento de cosas animadas tales como el retoño de una flor, el brote de un manantial, y también el acto de dar algo en ofrenda.

El modo de hacer femenino, tanto en el canto como en la escena ritual, se vincula con la manipulación de las jícaras (xukuri o sukuli según su pronunciación en el canto), sean las ofrendas o las jícaras-ancestro. En el patio ritual las mujeres ejecutan una secuencia que se repite en distintos momentos con pequeñas variaciones, desplazándose entre el altar, el centro del patio y el fuego con una jícara que contiene una mazorca de elote que llaman teiyari, « la Madre Maíz » que acogen con su manto y en el pecho (-wima). A modo de una secuencia paralelística, las variantes de esta secuencia establecen relaciones analógicas entre la cacería de venado, la fertilización del campo agrícola, la secuencia de barrer el patio y el sacrificio de la res, que produce un simbolismo que remite a la muerte, a la fertilidad y a la procreación ${ }^{16}$. En la primera parte del canto ritual, el hacer de las entidades femeninas (Tateteima) es descrito acto por acto a manera de una secuencia cinematográfica en cámara lenta, con una jícara en su manto que va adquiriendo rasgos humanos en pleno crecimiento (se le llama niña, joven, madre) en el curso de su desplazamiento desde el mundo de abajo o el lugar de la noche (Tłkaripa) hacia el plano medio del mundo en el centro (Hixłapa). La función genésica femenina es acentuada en pasajes que insisten sobre el motivo del nacimiento (nuiwari) y en la mención del gesto femenino (-wima) con el que las mujeres « acogen en su manto » la teiyari o el venado cazado, según la etapa del ciclo ritual. Este modo de hacer mimético crea las condiciones para la sincronía entre humanos y no humanos en el marco del anacronismo característico del ritual. La jícara descrita en su proceso de crecimiento conforma lo que llamamos la categoría-jícara ordenada en una estructura paralelística identificada a nivel macro del texto ritual, con la repetición sistemática de un término y la variación de otro (ver Figura 4).

\begin{tabular}{|c|c|c|}
\hline Segmento & Término en wixárika & Término en español \\
\hline 30 & sukuli & jícara \\
\hline 31 & tei masa sukuli & madre venado jícara \\
\hline 72 & ‘imali sukuli & joven jícara \\
\hline 108 & nemuuta sukuli tïlli sukuli & $\begin{array}{c}\text { mi hermano menor jícara } \\
\text { niños jícara }\end{array}$ \\
\hline
\end{tabular}

16. La relación entre el barrido en el ritual y la fertilidad se ha destacado en la literatura mesoamericanista durante la fiesta de Ochpaniztli dedicada a la diosa Toci, en la cual la escoba figura como símbolo de la feminidad (Sahagún 2000 [1577], p. 250). Según un testimonio citado por S. Schaefer, el cargo de « tenantsi » se ocupa de barrer el patio ritual, y en tiempos antiguos correspondía a las mujeres aprendices de mara'akame (2002, p. 67, p. 83). 
Nuestra Madre Milpa Joven: una imagen de la totalidad efímera en un ritual wixárika

\begin{tabular}{|c|c|c|}
\hline 150 & tuutuli sukuli & flor jícara \\
\hline 150 & tasukuli & nuestra jícara \\
\hline 175 & tatei sukuli & nuestra madre jícara \\
\hline
\end{tabular}

Fig. 4 - Estructura paralelista de la categoría-jícara y sus variaciones.

El canto recrea el paralelismo observado en el plano de las secuencias, en el tratamiento lingüístico que produce el crecimiento de la mujer-jícara que hemos identificado como la mujer « que entrega la ofrenda » (timawame) en la escena ritual. La mujer-jícara, con su modo de actuar sigiloso y contraído, opera como contenedor de los artefactos que dan forma al ensamblaje de la Madre Milpa Joven y tanto en el patio ritual como en el canto se desenvuelve en interacción con su « retoño » (yírari), el hijo-flor xuturi cuya identidad se atribuye al joven sacrificador. La descripción acto por acto - de un tipo narrativo poco frecuente - toma una aparente linealidad que hemos abordado como una serie evolutiva que produce una temporalidad orientada por los términos lingüísticos en torno de las categorías polisémicas del wixárika tikari (temporada de lluvias, noche, oscuridad) y tukari (temporada de secas, luz, vida), con las que el cantador-chamán describe los procesos de transformación de los ancestros que emergen de la oscuridad para descubrir sus rostros con el nacimiento del sol y que hemos llamado el cronotopo de la agricultura (Lira, en prensa).

A la segunda categoría-vara de plumas pertenecen los artefactos que median las relaciones entre las entidades masculinas (Kakajyama), con las que el cantador se identifica y cuyas identidades acumula en el curso de desplazamientos entre la región de en medio/Centro (Hixłapa) y de arriba/Este (Hixíata), y entre la derecha/Sur (Tserieta) y la izquierda/Norte ('Utata). Por ejemplo, en un pasaje dos artefactos, el tapete ('itari) sobre el cual el cantador esparce sus herramientas chamánicas, y el nierika, que designa una diversidad de objetos presentes en la escena ritual (el espejo que el cantador tiene frente a sí como parte de sus herramientas, el rostro del venado cazado que manipula en su mano, la piedra circular tepari que marca el centro del patio), son colocados simultáneamente en el centro. Al desplazamiento y depósito de artefactos les sucede un « retoño »- en lenguaje del canto - y el enunciador se designa a sí mismo «Yo soy Kauyumarie » (Kaunemarie) ${ }^{17}$. Con el uso de posesivos el contraste de perspectivas entre las entidades que manipulan tapete y nierika es acentuado, hasta que al final del canto se emplea el posesivo en plural « nuestro » (ver Figura 5, página siguiente).

17. Es importante destacar que, entre los cantos de la comunidad vecina de San Andrés Cohamiata, D. Lemaistre encontró la misma fórmula (1997, p. 142). 


\begin{tabular}{|c|c|c|}
\hline Segmento & Término en wixárika & Término en español \\
\hline 0 & tanierika & nuestro rostro \\
\hline 24 & yu'itari - nenierika & su tapete - mi rostro \\
\hline 59 & 'itari - nenierika & tapete - mi rostro \\
\hline 86 & 'itari - nierika & tapete - rostro \\
\hline 120 & ne'itali - senierika & mi rostro - sus rostros \\
\hline 133 & yunierika - ne'itari & su rostro - mi tapete \\
\hline 134 & ta'itari & nuestro tapete \\
\hline 153 & tanierika & nuestro rostro \\
\hline
\end{tabular}

Fig. 5 - Contraste de perspectivas en la categoría-vara de plumas.

Este contraste de perspectivas que distingue las intervenciones de las entidades masculinas es acentuado con el uso de deícticos de espacio (aquí, ahí, allá) que producen una espacio-temporalidad discontinua, que nos permite entender la cacería en términos de cronotopo central (Bahktin 1981 [1937-1938]), que a su vez cumple funciones tanto organizativas como composicionales del canto al centrarse en la relación simétrica (o de rivalidad) entre el venado presa y el tigre cazador en esta primera parte. El acto de caza que sucede, sucedió y sucederá de manera indefinida en el canto es el momento cronotópico por excelencia: el nudo de la trama. En este contraste de perspectivas figura el elemento inestable de la concepción de persona, que en el caso del enunciador implica que pueda asumir las identidades de las entidades con las que se identifica directa (en primera persona) e indirectamente (en segunda o tercera persona) - venado Kauyumarie, tigre Wawatsari, fuego Tewatsi ${ }^{18}$, sol Nekaiye -, o bien que estas identificaciones sean tanto acumulables como reversibles en el curso de sus desplazamientos en el mundo del canto que es transitable en múltiples sentidos y a diversas escalas (Lira, en prensa). Sin embargo esta acumulación no se realiza al infinito sino es mediada por una operación que al cabo de acumular o fusionar identidades, produce un desdoblamiento o fisión (López Austin 1983).

18. La traducción de Tewatsi como abuelo no es común. Esta traducción dada por los especialistas rituales que consulté se encuentra en un artículo del lingüista J. L. Iturrioz donde analiza el término tewa que considera " palabra clave para entender la estructura social tradicional y las relaciones de parentesco » (2002, p. 80). Ahí nos dice que tewari se emplea como término de parentesco religioso, para las entidades de « segundo rango », después de los bisabuelos como el « dios del fuego »: el « perfil mítico de la figura del abuelo como transmisor de conocimiento "; y con el honorífico -tsi conforma el término tatewari que designa en una relación simétrica tanto a abuelos reales como a nietos (ibid., p. 80-81) y señala que esta palabra deriva probablemente del tewa-kari « llamarse » y el término tewa también se aplica a todos los animales domésticos y máquinas semovientes (ibid., p. 81-82). 
Nuestra Madre Milpa Joven: una imagen de la totalidad efímera en un ritual wixárika

Por ejemplo, en el curso del nacimiento y manipulación de una vela (hauri), el tigre Wawatsari se desdobla en león 'Ututawi y se completa la serie de identificaciones. Manipulados en el mundo invisible de los antepasados, los artefactos que conforman las herramientas chamánicas del cantador se acumulan progresivamente en la región de en medio (el centro), y son visibles en el patio ritual frente al cantador que los tiene extendidos en su tapete ('itari): su vara de plumas (muwieri), su espejo y rostro de venado (nierika), su estuche (takwatsi), sus velas (hauri) y su cirio ('iteiri), restituyendo su identidad plural y compleja.

La tercera categoría-flor xuturi engloba los artefactos sacrificiales (mawari). En primer lugar, este término se traduce por « flor » aunque no tiene un referente botánico particular y es exclusivamente un término ritual que designa una diversidad de cosas asociadas con el sacrificio: las velas empleadas en las secuencias preparatorias del sacrificio, las flores en papel de china que decoran las velas y la res que será sacrificada. La xuturi o sutuli - según la pronunciación del canto - nace (múltiples veces) en lugares donde hay agua, camina, es entregada en ofrenda, es flechada, retoña, toma la voz, y al mismo tiempo se asocia con artefactos como las velas (hauri) ${ }^{19}$, la jícara (xukuri), y las cruces (kuruxi) ${ }^{20}$, los niños dios (yusi ẗ̈ri), un « Ancestro tierno » (kałye wenima) y entidades del mundo mestizo como Jesucristo (Kesusi), San José (Sakutsé), el Vaquero (Wakeru) o la Virgen de Guadalupe (Wirken Walalupi). Entre los artefactos que conforman esta tercera categoría-flor xuturi destaca un comportamiento que tiende a la acumulación y a la contracción, desplegando sobre todo relaciones de analogía y de oposición (ver Figura 6).

\begin{tabular}{|c|c|c|}
\hline Segmento & Término en wixárika & Término en español \\
\hline 42 & masa hauli kikit haulieya & venado vela kikkił ${ }^{21}$ su vela \\
\hline 73 & masa hauli tíwekari hauli & venado vela tigre vela \\
\hline 78 & matsi hauli kulusi hauli & hermano mayor vela cruz vela \\
\hline 94 & ttkari hauli & noche vela \\
\hline 95 & yusutuli/'anierika & su flor-xuturi tu rostro \\
\hline 97 & nesutuli tuutuli & mi flor-xuturi flor \\
\hline
\end{tabular}

19. La asociación entre la flor y la vela está registrada en el mito del sol registrado por R. Zingg (1982, II, p. 168-169).

20. Kuruxi puede ser traducido como « cruces » y también como «monedas ». Según J. L. Iturrioz (2004, p. 27), éstas son el « principio vital » $\mathrm{o}$ « alma » de las entidades cristianas.

21. No encontré este término en otras traducciones. Lo dejé en lengua original porque hasta le fecha no lo comprendo cabalmente. De su contexto de aparición en el canto se infiere su importancia, ya que su asociación con la flor-xuturi es una constante. Entre las interpretaciones obtenidas está la de venado, venado cazado, ofrenda, vaca que será sacrificada, vaca sacrificada, y animal doméstico. 


\begin{tabular}{|c|c|c|}
\hline Segmento & Término en wixárika & Término en español \\
\hline 100 & nekulusi/nesutuli & mi cruz mi flor-xuturi \\
\hline 103 & sesukuli sesutuli & su jícara su flor-xuturi \\
\hline 128 & nesutuli hauli & mi flor-xuturi vela \\
\hline 130 & 'ari' 'asutuli 'ari misewi & ya tu flor-xuturi, ya es uno \\
\hline 131 & kikił hauli & kìkił vela \\
\hline 138 & turi kìkił & flor kìkił \\
\hline 149 & tuli sukuli & flor jícara \\
\hline
\end{tabular}

Fig. 6 - Acumulación y contracción en la categoría-flor xuturi.

De manera semejante a la escena ritual, la xuturi se engendra de la relación entre relaciones. Es decir que la diferencia sexual (vía la vela y las jícaras) detona otro nivel relacional que establece un vínculo con las entidades del mundo mestizo (vía las cruces). El canto finalmente dice « tu flor-xuturi ya es uno » y con ello, se atribuye a la Madre Maíz Niwetsika (Niwetsika sutuliyu). En la primera parte del canto se vislumbra lo que llamamos el cronotopo del sol, si bien apenas es la medianoche. De este campo de transformaciones y de sus constantes se propuso que la xuturi u ofrenda en sacrificio (mawari) es simultáneamente ancestro (-kaìye), descendiente (-nuiwari) y también mestizo, lo que nos remite al mito del nacimiento del sol (huichol y mesoamericano) en el que un niño « pobre e inválido » se auto-sacrifica en la hoguera y asciende al cielo como Takatye o «Sol Mayor » trayendo enfermedades, según la traducción de R. López de la Torre (2006, p. 34), y que en otros relatos es concebido como foráneo o vecino mestizo (Lemaistre 1997, p. 251). Vale recordar las concepciones mesoamericanas que asocian la guerra con la cacería y también con el parto femenino, lo cual permite considerar que el sol pueda ser concebido como enemigo engendrado (Olivier 2011, p. 78-79) 22 .

Los artefactos-persona producidos colectivamente en el curso de las interacciones en el patio ritual, así como las personas-artefacto complejizadas en el curso de la enunciación del canto que serán ensamblados sobre la mujer-jícara, dan cuenta por lo tanto de un complejo entramado socio-cósmico. En estos

22. En un canto de la ofrenda (mawarixa), D. Lemaistre encuentra que el sol se designa como teiwari (1997, p. 251), es decir vecino o foráneo, y en un mito documentado por R. López de la Torre se describe como el que trae enfermedades como la varicela o el sarampión entre otras (2006, p. 24-25). Esta interpretación del sol como enemigo es parte de una discusión mesoamericanista. En un libro sobre la cacería de venado y la guerra en el México prehispánico, Olivier reproduce una imagen del Códice Borgia en la cual la entidad de la gestación Tlazoltetol se representa como un prisionero en forma de un niño y que porta en un collar (2011, p. 78-79). 
artefactos están implicadas relaciones de depredación y afinidad potencial entre cazador y presa, de consanguinidad y de guerra entre madre e hijo, o bien de alteridad entre hijo-sol y entidades mestizas. Pensar en la Madre Milpa Joven en términos de imagen-persona, como la antropología del arte reciente nos ha enseñado a entender, eclipsaría las relaciones acumuladas e implicadas en su uso y los modos de hacer que las han producido, el cual conduce hacia la co-actividad entre humanos y antepasados acentuada en el uso del posesivo del plural « nuestro » (nuestra jícara, nuestro tapete) y que da cuenta de la complejidad ritual en juego. A este proceso de sincronización se superpone el de la simultaneidad de los espacios-tiempo multiplicados en el canto, que crea las condiciones para que el cantador alcance uno de sus grandes retos: el de articular - enlazar o tejer según el lenguaje del canto - los distintos centros del canto (el patio ritual, la fogata, el altar, la milpa, el lugar de caza, la flecha, el nierika, el tapete, etc.) en un mismo tiempo-espacio que es el aquí-ahora del ritual (Lemaistre 2003, p. 184; Benzi 1972, p. 107-108)23. Esta habilidad chamánica de ordenar el axis mundi como « síntesis del mundo » es una de las múltiples definiciones de nierika que O. Kindl (2007, p. 2254-2255) ha propuesto desde el arte ritual, y que en el canto se llama hixiapa, el lugar del centro, el punto origo del canto, punto de partida y también de llegada. Este centro-aquí-ahora de la enunciación forja un presente « fecundo », según la expresión de J. Negrín (1985, p. 29-30), del que emerge la Madre Milpa Joven como un momento de síntesis, siguiendo a $\mathrm{O}$. Kindl, pero que es, y debe ser, irremediablemente efímero. Volvamos al patio ritual.

\section{El mediodía « se prenden las velas »}

La puesta en forma y en acto de la Madre Milpa Joven se produce en la última secuencia «se prenden las velas » (haurimantiyani), casi al final de la fiesta. Al medio día y en el centro del patio ritual (centro del mundo, hixiapa), los elementos heterogéneos que la componen son colocados uno sobre otro: sobre la piedra (tepari - nierika) en el centro del espacio ritual se coloca la mujer-jícara timawame hincada y mirando al Este. Sobre su cabeza se coloca la caja que contiene las ofrendas: las flechas (hombres venado), las jícaras (mujeres maíz), los discos votivos (cantador chamán) y las velas, y también los cuernos

23. Por medio de analogías a distintos niveles, se enfatiza este esfuerzo por unir y enlazar. Las diferencias acentuadas entre actores rituales al inicio del ritual van dando paso a una imbricación progresiva en el plano de las acciones que exaltan la totalidad grupal. Esto se realiza por ejemplo durante la secuencia anterior al sacrificio, en la que la cuerda con la que se ató la vaca durante toda la noche ata simbólicamente a todos los participantes del ritual, rodeando al grupo familiar y el espacio ritual, primero en sentido levógiro y en seguida en sentido horario. Así, el grupo familiar, el joven sacrificador, los niños haakeri, entre otros elementos, son asociados simbólicamente en distintos momentos con la ofrenda sacrificial mawari. 
y rostro del venado cazado, los cuernos de la res, su corazón e hígado recién extirpados en el amanecer (víctimas sacrificiales sol-mestizo). Sobre la caja y a manera de abanico se colocan verticalmente velas que se prenden. En el zénit está el sol de mediodía. El cantador, frente a ella, prosigue su canto, el Cazadorvenado y el Sacrificador-res esparcen sangre de sus víctimas sacrificiales (o de sí mismos) sobre cada una de las ofrendas, y el conjunto de mujeres-madres rocían agua proveniente de los manantiales sagrados con polvo de maíz azul en las ofrendas. Todos estos elementos guardan contacto entre sí, y las personas cuidan de mantener contacto físico entre ellas. A este conjunto se le atribuye la identidad de Nuestra Madre Milpa Joven o Tatei Waxa ‘imari « o la Virgen de Guadalupe ó la Madre Maíz Niwetsika, pues es lo mismo », según se me ha dicho en repetidas ocasiones (ver Figura 7).

En el momento de su conformación provoca llantos entre sus creadores y una mirada triste entre sus observadores, quienes me han comunicado las inquietudes que les susita: « ¿por qué la Madre Maíz Niwetsika se nutre de tanta sangre?, ¿cómo vamos a hacer para pagar más vacas? » Como la cristalización en imagen de todo un ciclo, sus partes son eventualmente desagregadas y la fiesta casi ha llegado al final. En unas horas se comparten alimentos y bebida en abundancia y al día siguiente se concluye en el coamil en el cual se vierten caldos, agua con chocolate, sangre y peyote. El coamil/milpa es también centro del mundo - el lugar de inicio y de término de todo ritual - la quinta dirección, hixiapa. En las semanas siguientes las ofrendas y partes sacrificadas serán entregadas a los distintos ancestros-topónimos, manteniendo el « andar » wixárika, concepto con el que las sociedades wixaritari designan « el costumbre » (yeiyari, « andar/caminar »).

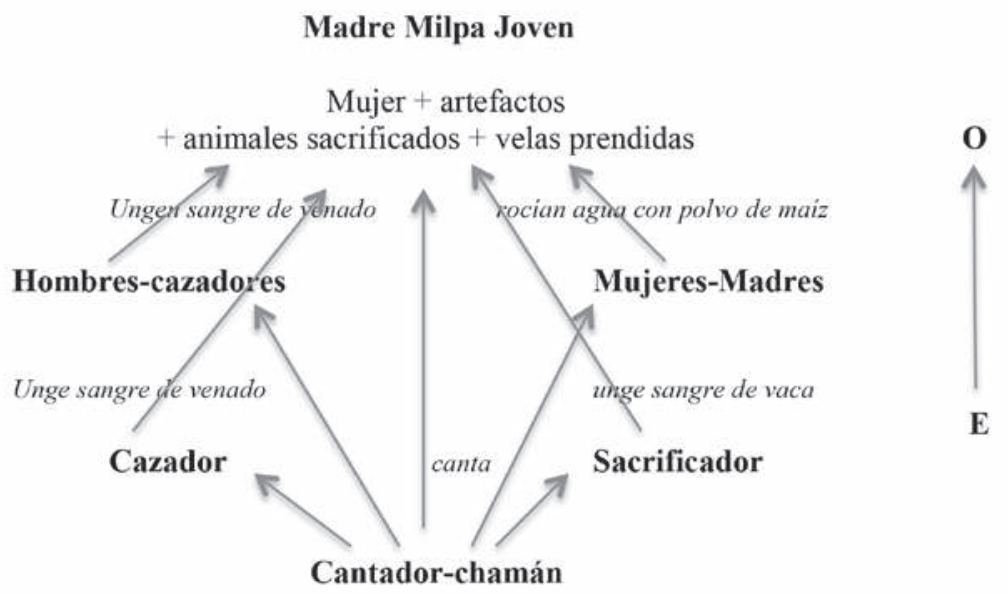

Fig. 7 - Configuración en torno a la mujer-jícara « que entrega la ofrenda ». 
Si humanos y ancestros hacen lo mismo, o son lo mismo, ¿quién es entonces el creador de esta imagen de la transformación? Hemos mostrado cómo cada parte de este objeto complejo es índice de relaciones directas e indirectas que se afectan de parte a parte y de parte a todo: un « objeto de arte » que A. Gell designa como dotado de « agencia intencional compleja » $(1998)^{24}$. Su autonomía aparente, que de manera concomitante funda su autoridad, se explica no a partir de la intervención directa de uno u otro participante, sino más bien por una serie de identificaciones parciales que animan el conjunto de relaciones implicadas por su uso (Severi 2008, p. 117). Como objeto estrictamente relacional, resultante de la configuración de diversos registros de acción y de una superposición de planos relacionales, las relaciones que en ésta se han acumulado se han colapsado sobre ella misma, mostrando su forma única que todos reconocen de manera inequívoca: se trata de la Madre Milpa Joven.

En el ensamblaje de la Madre Milpa Joven se han acumulado relaciones a diversas escalas que la acción colectiva ha enlazado, lo cual nos lleva a entenderla como la imagen que la sociedad wixárika forja de sí misma al englobar a las personas y a sus antepasados en un «solo corazón-memoria »" Si en el acto creativo se originan las condiciones de posibilidad para la coexistencia efímera de los mundos humanos y no humanos, es en la experiencia colectiva de su creación en donde reside su potencia y se difuminan sus contornos. Como lo expresaba justamente J. Negrín en uno de sus textos clásicos sobre el arte ritual huichol, en las ceremonias « los Antepasados son invocados, atraídos por los cantos de los maracate, las libaciones, el sacrificio animal, y complacidos por los esfuerzos de sus descendientes humanos; les prestan nuevas fuerzas al 'iyari y les refrescan el alma cupuri con rocío. En esta forma se fusionan el espíritu inmanente de los Antepasados y el espíritu latente de los hombres, en una correspondencia entre

24. Me he basado en un ejemplo proporcionado por A. Gell en Art and agency, en el cual propone que el principio que anima una " pirámide humana » formada por un equipo de acrobacia que designa como " self-made index » se basa en las relaciones agente/paciente a niveles «part-to-part » $\mathrm{y}$ " part-to-whole » que se afectan al interior del objeto (1998, p. 41-45). En su célebre ensayo de 1996 (2006, p. 233) define objeto de arte: «I would define as a candidate artwork any object or performance that potentially rewards such scrutinity because it embodies intentionalities that are complex, demanding of attention, or perhaps difficult to reconstruct fully. " Si ahora reconocemos que la aproximación relacional a la imagen es una aportación de la etnología melanesia, el análisis se ha refinado gracias a su puesta a prueba en otros contextos etnográficos y desde la teoría sobre el ritual, como por ejemplo en Amazonía (Fausto y Severi 2014).

25. Esta idea se encuentra en el discurso ritual. J. Negrín lo explica en los siguientes términos: «En esta forma, las familias de las rancherías dispersas entran también en comunión tribal; su sangre, gruesa de siglos de unión espiritual, fluye de cuerpo en cuerpo, como fluyen los ríos al mar, todos se forman "de un solo corazón": "ta iyari yari" » (1985, p. 30). También está la idea de « un solo camino » (Mata Torres 1974, p. 24-26), que remite al andar wixárika. 
el macrocosmo y el microcosmo que se sostienen mutuamente, inyectándose lo eterno dentro del fecundo presente » (1985, p. 29-30).

\section{La Madre Milpa Joven como totalidad efímera}

Como me ha explicado un amigo de la comunidad de Tuapurie: « el mundo es uno aunque lo percibamos como dividido, en partes: en montañas, ríos, nubes, etc. "). A la pregunta sobre cómo esas partes - heterogéneas a mis ojos conforman un todo, el arte ha intentado responder de múltiples maneras. Entre los formalistas rusos, M. Bakhtin (1990 [1920-1923], 1990 [1924]) planteaba esta pregunta en sus escritos tempranos, enfatizando la heterogeneidad antes que la unidad del objeto estético que perfiló en su definición de arquitectónica como actividad que ordena las relaciones entre el yo y el otro en un estado de tensión dinámico; posiciones que son tanto relativas como simultáneas, dadas en el marco de la experiencia a partir de la cual desarrolla su concepto de dialogismo. Esta reflexión que enfatizaba el carácter plural de la creación artística pareciera lejana o ajena a la huichola. Más me ha estimulado cuestionar cómo este ensamblaje « enlaza » la unidad o completitud que no es el estado ordinario de las cosas, sino algo que se busca y se alcanza de manera irremediablemente efímera. El concepto de nierika como modo de conocimiento indígena - siempre riesgoso - comprende en sí esa pregunta: la de ver (del verbo nieriya), conocer, comprender « la totalidad » (Kindl 2007, p. 329).

El ensamblaje Madre Milpa Joven nos ha permitido hacer un recorrido por todo un ciclo y ha puesto en evidencia su vínculo con la concepción nativa de 'iyari o corazón-memoria. Primero como dispositivo mnemónico, al ser una construcción sinóptica de todo un ciclo ritual, y en segundo lugar como espacio de experiencia y de conocimiento compartidos y ordenados. Esta experiencia remite a los riesgos compartidos entre los hombres durante la cacería, entre las mujeres que los esperan y los apoyan, entre familiares que viven dispersos en rancherías lejanas y que se reúnen para la ocasión, y también de la experiencia con los otros: la otra mujer, el otro depredador, el otro enemigo, el otro mestizo. Como « imagen », ésta colapsa o condensa el contexto en sí misma, lo cual detona su reconocimiento y al mismo tiempo se vincula con los « eventos » más valorados en la historia wixárika, transmitidos en el ritual que es la historia de cómo los antepasados crean, crearon y crearán el mundo en cada ritual « como si fuera la primera vez ». Como creadora de su propia temporalidad, las partes de este entramado permiten hacer un recorrido por esta historia que es historia en presente, pasado y futuro, pero que no se restringe a una lectura lineal sino que puede recorrerse en sentido reversible o a manera de un fractal pasando de un nivel micro al macro. Como imagen anacrónica que es muchos tiempos a la vez, surge la pregunta del tiempo de su creación: esto es un tiempo colapsado en un presente, fecundo y desmultiplicado. 
Nuestra Madre Milpa Joven: una imagen de la totalidad efímera en un ritual wixárika

Finalmente, las jícaras, las flechas, la velas, el venado, los cuernos, etc. son parte de un repertorio gráfico presente en la gran mayoría de cuadros de estambre huicholes realizados para la venta. Con esto se sugiere que estos artefactos-imágenes conforman un repertorio exclusivo que pueden combinarse en configuraciones cada vez más complejas, y cuyo contexto de uso orienta sus posibles interpretaciones. En el orden impuesto por este ritual agrícola en torno de una madre-jícara « que entrega la ofrenda », su interpretación como Madre Milpa Joven detona otra memoria transmitida en los cantos y el discurso mitológico. La de la madre dadora de vida, la que sacrifica a su hijo, la que porta una falda de estrellas, la que es maíz, virgen y mexicana ${ }^{26}$. Las ideas warburguianas que tanto J. Assman (1995, 2006) como C. Severi (1996, 2007) han retomado en torno de la imagen como huella mnémica convergen en el aspecto trágico o doloroso que juega en su pervivencia. En este sentido, el maíz es efectivamente un detonador de una historia de sacrificios sin fin que involucra a cada persona en el presente y la vincula con el pasado. Posiblemente esta fuerza trágica que se prolonga en la imagen haga del nacimiento del maíz uno de los grandes temas gráficos representados en el arte huichol de tablas de estambre, y también del arte mesoamericano, que a manera de figura intermedia entre el arte y el ritual se transmite restituyendo el continuo vivencial entre el presente y el pasado. *

* Manuscrit reçu en mai 2015, accepté pour publication en octobre 2016.

Agradecimientos - Agradezco al Programa de Becas Posdoctorales de la Universidad Nacional Autónoma de México por el apoyo brindado a los jóvenes investigadores. Agradezco de manera especial a Isabel Martínez, Johannes Neurath y Federico Navarrete por sus comentarios durante la elaboración de este artículo. Y también a los lectores cuyos dictámenes acertados e impecables me permitieron refinar la versión final de este artículo, primer producto derivado de mi tesis doctoral.

26. Según distintas fuentes encontramos que Tatei Waxa 'imari es una madre que lleva una falda de estrellas (Lumholtz 1907a, p. 14) y sacrifica a su hijo en Teupa, lugar donde se arrojó el niño a la hoguera que emergió del otro lado del mundo como niño sol (según canto de San Francisco registrado por D. Lemaistre 1997, p. 304), o bien que abandona a su hija la lluvia del oriente, Nłariwame (Medina 2012, p. 22, comunidad de Durango). Además, en D. Lemaistre (1997, p. 49) se dice que es la hermana del ancestro Cola de Venado - Maxa Kwaxí quien logra robar los primeros peyotes a los guardianes del desierto, los namakate. En J. Ramírez de la Cruz (2003-2004, p. 102) se la asocia con la Virgen de Guadalupe, como creadora de la música estilo regional. Está a la vez próxima a Tatei 'Utíanaka, a quien también se atribuye ser madre del niño venado que se sacrificó para que saliera el sol (¿su « hermana » o su « doble »?) vía Werika ‘imari (Kindl 2003, p. 91; Lemaistre 1997; Lumholtz 1907a, p. 11), y tal como constaté en el trabajo de campo. 


\section{Referencias citadas}

AsSman Jan

1995 «Collective memory and cultural identity », New German Critique, 65, p. 125-133.

2006 Religion and cultural memory, Stanford University Press, Stanford.

BAKHTIN Mikhail M.

1981 «Forms of time of the chronotope in the novel. Notes toward a Historical Poetics ", in The dialogic imagination. Four essays, University of Texas Press (University of Texas Press Slavic series, 1), Austin, [1937-1938], p. 84-259.

1990 "Author and hero in aesthetic activity », in Michael Holoquist y Vadim Liapunov (eds.), Art and answerability. Early philosophical essays by M. M. Bakhtin, University of Texas Press (University of Texas Press Slavic series, 9), Austin, [1920-1923].

1990 "The problem of content, material and form in verbal art», in Michael Holoquist y Vadim Liapunov (eds.), Art and answerability. Early philosophical essays by M. M. Bakhtin, University of Texas Press (University of Texas Press Slavic series, 9), Austin, [1924].

BATESON Gregory

1958 Naven, Stanford University Press, Stanford.

BenZi Marino

1972 Les derniers adorateurs du peyotl, Gallimard, Paris.

BLoch Maurice

1974 «Symbols, song, dance and features of articulation. Is religion an extreme form of traditional authority? », in Archives européennes de sociologie, 15 (1), p. 54-81.

Fausto Carlos y Carlo Severi (coord.)

2014 L'image rituelle, L'Herne (Cahiers d'anthropologie sociale, 10), Paris.

FrEEDBERG David

1989 The power of images. Studies in the History of theory of response, University of Chicago Press, Chicago.

Furst Peter T. y Stacy Schaefer

1996 People of the peyote. Huichol Indian history, religión y survival, University of New Mexico, Albuquerque.

FURST Peter

1972 Mitos y Arte huichol, SepSetentas, México.

GeLl Alfred

2006 « Vogel's net: traps as artwork and artwork as traps », in Howard Morphy y Morgan Perkins (eds), The anthropology of art: a reader, Blackwell Publishing, Oxford, [1996].

1998 Art and agency, an anthropological theory, Oxford University Press, New York.

1999 «Strathernogramms or the semiotics of mixed metaphors », in The art of anthropology: essays and diagrams, Athlone Press (London School of Economics on Social Anthropology, 67), New Brunswick (NJ), p. 29-75. 
Nuestra Madre Milpa Joven: una imagen de la totalidad efímera en un ritual wixárika

Grimes Barbara F. y Joseph E. Grimes

1962 «Semantic distinctions in Huichol (Uto-Aztecan) kinship », American Anthropologist, 64 (1), p. 104-114.

GutiérRez del Ángel Arturo

2002 La peregrinación a Wirikuta. El Gran Rito de Paso de los Huicholes, Instituto Nacional de Antropología e Historia (Etnografía de los pueblos indígenas de México. Serie Estudios monográficos, 2002-1), México.

HANKS Williams

2009 « Comment établir un terrain d'entente dans un rituel?», in Carlo Severi y Julien Bonhomme, Paroles en actes, L'Herne (Cahiers d'anthropologie sociale, 5), Paris, p. 87-113.

Houseman Michael y Carlo SeVeri

1994 Naven ou le donner à voir. Essai d'interprétation rituelle, CNRS Éditions/ Ed. Maison des Sciences de l'Homme, Paris.

Houseman Michael

2000 «Ce que parler ne saurait dire: identités équivoques chez les Beti du Sud-Cameroun », in Jean-Luc Jamard, Emmanuel Terray y Margarita Xanthakou (eds), En substances. Textes pour Françoise Héritier, Fayard, Paris, p. 115-134.

2006 «Relationality », in Jens Kreinath, Jan Snoek y Michael Stausberg (eds), Theorizing rituals. Classical topics, theoretical approaches, analytical concepts, annotated bibliography, Brill/NUMEN-Bookseries, Leiden, p. 413-428.

2012 Le rouge est le noir. Essais sur le rituel, Presses universitaires du Mirail, Paris.

Humphrey Caroline y James LAIDLAw

1997 The archetypal actoins of ritual. A theory of ritual illustrated by the Jain Rite of worship, Clarendon Press, Oxford.

ITURRIOZ José Luis

2002 «Principios generales de la cultura huichola » Reflexiones sobre la identidad étnica, Universidad de Guadalajara, Guadalajara, [1995], p. 79-93.

2004 «Reconstrucción del contacto entre lenguas a través de los préstamos », in Lenguas y literaturas indígenas de Jalisco, Secretaría de Cultura Gobierno del Estado de Jalisco, Guadalajara, p. 23-121.

KINDL Olivia

2003 La jícara huichola. Un microcosmos mesoamericano, INAH/Universidad de Guadalajara, México.

2007 Le nierika des Huichol: un « art de voir », tesis de doctorado en etnología, université Paris Ouest Nanterre La Défense, Paris.

Lemaistre Denis

1997 La parole qui lie, tesis de doctorado en anthropologie sociale et ethnologie, École des hautes études en sciences sociales, Paris.

2003 Le chamane et son chant, L'Harmattan, Paris.

LifFMAn Paul

2011 Huichol territory and the Mexican nation. Indigenous ritual, land conflict and sovereignity claims, University of Arziona Press, Tucson. 
LIRA Regina

2014 L'alliance entre la Mère maïs et le Frère aïne cerf: action, chant et image dans un rituel wixárika (huichol) du Mexique, tesis de doctorado en antropología social y etnología, École des hautes études en sciences sociales, Paris.

(en prensa) «Caminando en el lugar del día (tukari), caminando en el lugar de la noche (tłkari): primer acercamiento al cronotopo en el canto ritual wixárika (huichol) », in Guilhem Olivier y Johannes Neurath (coord.), Mostrar y ocultar en el arte y los rituales: perspectivas comparativas, Instituto de Investigaciones Históricas, Instituto de Investigaciones Estéticas, UNAM, México.

LóPEZ Austin Alfredo

1983 « Notas sobre la fusión y fisión de los dioses », Anales de Antropología, 20 (2), p. 75-87.

LÓPEz De LA Torre Rafael

2006 El respeto a la naturaleza, legado de los antepasados Wixarika, Amaroma Editores, Guadalajara.

Lumholtz Carl

1907a «Symbolism of the Huichol Indians », in Memoirs of the American Museum of Natural History, vol. III. Anthropology, New York, vol. I.

1907b « Decorative Art of the Huichol Indians », in Memoirs of the American Museum of Natural History, vol. III. Anthropology, New York, vol. II.

MANZARES Alejandra

2003 El sistema de cargos de los xukurikate: parentesco y poder en una comunidad wixárika, UNAM, México.

Mata Torres, Ramón

1974 El pensamiento huichol a través de sus cantos, Editorial Kérigma, Guadalajara.

Medina Miranda Héctor

2012 Relatos de los caminos ancestrales. Mitología wixarika del sur de Durango, Miguel Ángel Porrúa/Universidad Autónoma de San Luis de Potosí (Antropología), México.

Moxey Keith

2013 Visual time: the image in history, Duke University Press, Durham.

NegRín Juan

1985 Acercamiento histórico y subjetivo al huichol, EDUG/Universidad de Guadalajara, Guadalajara.

NeURATH Johannes

2002 Las fiestas de la Casa Grande. Procesos rituales, cosmovisión y estructura social en una comunidad huichola, INAH/Universidad de Guadalajara, México.

2008a «Cacería ritual y sacrificios huicholes: entre depredación y alianza, intercambio e identificación », Journal de la Société des américanistes, 94 (1), p. 251-283.

2008 b « Alteridad constituyente y relaciones de tránsito entre los huicholes: iniciación, anti-iniciación y alianza », Cuicuilco, 15 (42), p. 29-44.

2013 La vida de las imágenes. Arte huichol, Artes de México, México.

OLIVIER Guilhelm

2011 «Cerfs mélomanes et chasseurs lubriques: chasse, musique et érotisme dans l'ancien Mexique », in Nathalie Ragot, Sylvie Peperstraete y Guilhem 
Nuestra Madre Milpa Joven: una imagen de la totalidad efímera en un ritual wixárika

Olivier (dir.), La quête du serpent à plumes. Arts et religions de l'Amérique précolombienne. Hommage à Michel Graulich, Brepols Publishers (Bibliotheque de l'École des Hautes Études, Sciences Religieuses), Paris.

Pitrou Perig

2012 «Figuration des processus vitaux et co-activité dans la Sierra Mixe de Oaxaca (Mexique) », L'Homme, 202, p. 77-111.

Preuss T. Konrad

1998 «Viajes a través del territorio de los huicholes en la sierra Madre Occidental », in Konrad T. Preuss, Eduard Seler, Johannes Neurath y Jesús Jáuregui (coords.), Fiesta Literatura y magia en el Nayarit. Ensayos sobre coras, huicholes y mexicaneros de Konrad Theodor Preuss, INI/CEMCA, México, [1907], p. 171-199.

1998 «Resultados etnográficos de un viaje a la sierra Madre Occidental », in Konrad T. Preuss, Eduard Seler, Johannes Neurath y Jesús Jáuregui (coords.), Fiesta Literatura y magia en el Nayarit. Ensayos sobre coras, huicholes y mexicaneros de Konrad Theodor Preuss, INI/CEMCA, México, [1908], p. 235-260.

RAMIRÉZ DE LA CRUZ Julio Xitákame

2003-2004 « Wixarika Xaweri », Revista Función, 27-30, p. 3-309.

SAHAGÚn Bernardino Fray

2000 Historia general de las cosas de la Nueva España, II, Conaculta (Cien de México), México, [1577].

SCHAEFER Stacy

2002 To think with a good heart. Wixárika women, weavers, and shamans, University of Utah Press, Salt Lake City.

SCHIEFFELIN Edward

1985 «Performance and the cultural construction of reality », American Ethnologist, 12, p. 707-724.

SEVERI Carlo

1996 La memoria ritual, locura e imagen del Blanco en una tradición chamánica Amerindia, Ediciones Abya-Yala, Quito.

2002 « Memory, reflexivity and belief. Reflections on the ritual use of language », Social Anthropology, 10 (1), p. 23-40.

2003 «Pour une anthropologie des images. Histoire de l'art, esthétique et anthropologie », L'Homme, 165, p. 7-10.

2007 Le principe de la chimère: pour une anthropologie de la mémoire, Éditions Rue D’Ulm/Musée du quai Branly, Paris.

2008 «Autorité sans auteur. Formes de l'autorité dans les traditions orales », De l'autorité, colloque annuel [18-19 octobre 2007, Collège de France], Odile Jacob, Paris, p. 93-123.

STRATHERn Marilyn

1990 The Gender of the Gift, University of California Press, Los Angeles.

2013 " Artifacts of history: events and the interpretation of images », in Marilyn Strathern, Learning to see in Melanesia. Four lectures given in the Department 
Regina LiRA LARIOS

of Social Anthropology, Cambridge University, 1993-2008, HAU Books (Master Class Series 2), Chicago, p. 157-178.

WeIGand Phil

1992 Ensayos sobre el Gran Nayar. Entre coras, huicholes y tepehuanes, CEMCA/ INI/Colegio de Michoacán, México.

YATES Frances A.

2004 L'Art de la mémoire, Éditions Gallimard, Paris, [1975].

ZINGG Robert M.

1982 Los huicholes. Una tribu de artistas, I, II, Libros de México SA, México, [1938]. 